\title{
Developing an Indigenous Goal-Setting Tool: Counting Coup
}

Turtle Island Journal of Indigenous Health

Vol. 1(1), 49-57

(C) The Author(s) 2020

https://doi.org/10.33137/tijih.v1i1.34007

\section{litáa Dáakuash (Rae Birdhat-Howe), Alma Knows His Gun McCormick, Shannen Keene, John Hallett, \& Suzanne Held ${ }^{1}$}

Chronic illness self-management best practices include goal-setting; however, the goal theory that many tools employ relies on individualistic principles of self-efficacy that are not culturally consonant within many Indigenous communities. During the creation of the Báa nnilah program, a chronic illness self-management intervention, we developed a goal-setting tool specific to the Apsáalooke Nation. Emerging from an Indigenous paradigm and methodology, Counting Coup serves as a goal-setting tool that promotes the Apsáalooke culture, connects individuals with their ancestors, and focuses on achievement of goals within relationships. Future research and practice should be grounded in the historical and cultural contexts of local communities when designing and implementing goal-setting tools. Limitations to Counting Coup as a goal-setting tool include the need for program facilitators to have a relationship with participants due to Counting Coup's foundation in relational accountability and that the environmental context may pose difficulties for participants in moving towards healthy behavior change.

\section{Keywords}

Chronic illness, Indigenous research methods, Community-based participatory research, Goalsetting

\section{Introduction}

Before colonization, Counting Coup was the highest honor a warrior could achieve in many plains Indigenous tribes, including the Apsáalooke (Crow) Nation. A warrior could Count Coup by touching an enemy with their hand or coup stick and coming away unharmed, showing superiority over their enemy. After Counting Coup, the warrior could add a feather to

\footnotetext{
Acknowledgements: We are grateful for the following funders: Montana Healthcare Foundation, The Mountain West Clinical Translational Research Program, National Institute of General Medical Sciences, NIH 1U54GM104944; Montana INBRE, National Institute of General Medical Sciences, NIH, P20GM103474; Improving Chronic Illness Management with the Apsáalooke Nation: The Báa nnilah Project, NIH, U01MD010619. The content is solely the responsibility of the authors and does not represent the official views of NIH.

${ }^{1}$ Department of Health \& Human Development, Montana State University, suzanne@montana.edu
}

their coup stick. Today, chronic illness is an enemy for Indigenous people, including the Apsáalooke Nation. For example, American Indian and Alaska Natives over 18 years of age are 2.4 times more likely to be diagnosed with diabetes (Centers for Disease Control and Prevention, 2016).

One way to address these disparities is through research; however, research conducted in Indigenous communities has often been referred to as "helicopter research", meaning the research did not benefit communities and was done on, rather than with them (Sobeck, Chapleski, \& Fisher, 2003). The Apsáalooke community has had this experience and our research works to counter deficit-based, extractive research by using Indigenous research methods (IRM) and a community-based participatory research (CBPR) approach. IRMs place emphasis on the social, historical, and political contexts that have shaped Indigenous experiences, lives, positions, and futures (Martin \& 
Mirraboopa, 2003). IRM includes a conversational method where knowledge is gained through oral storytelling within and through relationships. These are "relationships not just with people or objects, but relationships that we have with the cosmos, with ideas, concepts, and everything around us" (Wilson, 2001, p. 177). We build these relationships through developing shared understandings of commonalities, such as who we are related to, and is facilitated by social activities such as basketball and cultural events - we call this relationality (Kovach, 2009).

Community-based participatory research is an approach where the community guides research topics based on their own strengths and resources (Israel et al., 1998; LaVeaux \& Christopher, 2009). It works to equally distribute power amongst the research team and seeks to foster a true collaborative effort to develop and implement programs that are beneficial for the community (Minkler \& Wallerstein, 2008).

This research was conducted through a partnership between Messengers for Health (MFH), a non-profit organization located on the Apsáalooke Reservation in Montana and faculty and students from Montana State University (MSU). MFH's mission is to strengthen community capacity by empowering individuals to assess and address their own unique health-related knowledge, attitudes, and behaviors. The partnership began in 1996 to address a community-identified issue of low cancer screening rates. Program ideas came from the community and were communicated through history, story, humor, relationality, and conversational methods. In 2013, our community advisory board (CAB) determined that working to help community members who have chronic illness would be our next focus area.

Past programmatic research on improving chronic illness self-management has been primarily developed for and tested in the majority population (Barlow et al., 2002; Lorig et al., 2013). Much of the research on chronic illness self-management interventions has occurred using the Stanford University-developed Chronic Disease Self-Management Program (CDSMP). Some of this research has occurred in Indigenous communities and includes Warren and colleagues (2005), who modified and implemented the CDSMP in rural Australia and Blue Bird Jernigan (2010), who made minimal changes to the CDSMP and implemented the program in a US urban Indian health clinic. While innovative, both programs experienced difficulties translating the program into the local community and sustaining engagement.

The difficulties these programs experienced are not surprising. It is understandable that there is resistance to research, to programs being developed for minority communities by the dominant society, and to adapting programs developed for the majority population. The dominant society imposing their will on those they have colonized, have caused the health disparities we are working to address. This behavior is endemic to society (Brayboy, 2005). For example, there are direct links between consumption of commodity foods and unhealthy states (Gordon \& Oddo, 2012; Shanks et al., 2016).

We focus on the communities' voice in describing their own health disparities and how the community wants to address them. We rooted our program development process within the lived experiences of Apsáalooke people. Acknowledging and understanding local cultures and developing programs specific to these cultures reaffirms the power inherent in individuals in ways that only they can truly feel.

We developed our chronic illness self-management program, titled Báa nnilah, using community members' experiences with chronic illness. In the Apsáalooke language, Báa nnilah means the cultural practice of sharing advice with others, often through stories. Twenty community members shared their life stories and what makes it easier and more difficult for them to manage their chronic illness. As a team we listened to their stories and discussed what touched our hearts. We co-developed a new method for data analysis in order to keep stories together and honor community voices, so as to not break-up stories into pieces for data analysis, as is the case in content or thematic analysis (Hallett et al., 2017). Community members who are doing well managing their chronic illness facilitate seven gatherings with ten community members who are interested in learning to better manage their chronic illnesses. The content and approach for each of the gatherings arose from data analysis discussions (Held, et al., 2019; Schure, et al., 2020).

One activity we wanted to include in our program was goal-setting. Goal-setting is an integral component of chronic illness self-management programs (Institute for Healthcare Improvement, 2018; Institute of Medicine [IOM], 2012; Nuovo, 2007), and 
goal theory (Lock \& Latham, 1990; 2006) informs many goal-setting exercises in these programs. Often program participants choose from a list of potential goals or identify a health-related goal they would like to achieve. Participants are taught to make their goals specific, measurable, achievable, realistic, and timely (Australian Government Department of Health and Ageing \& Flinders University, 2009). Typically, they then identify potential barriers to achieving their goal and strategies for overcoming these barriers (IOM, 2012; Antonucci, 2008).

Goal-setting theory and its application emerged from a Western mindset. Consequently, they are not appropriate for Apsáalooke community members due to conflicting epistemologies. In the Indigenous worldview, stories provide insight into ways of being and knowing - they are our culturally validated theories. At the time of developing our goal-setting tool, we were unable to locate publications that discussed goal-setting from a non-Western perspective or that used IRM.

When using IRM, it is crucial for researchers/ authors to place themselves and to describe the community; therefore, we will do this here. For additional information on the Apsáalooke Nation see Linderman (2003); Medicine Crow (1992); Medicine Crow \& Viola (2006); and Snell (2000).

My name is Iitáa Dáakuash (always has a good place to be) or Rae Birdhat-Howe, and I have lived on the reservation over 20 years, identify as a Crow woman, and I consider myself an active member of my community. Growing up on the rez and moving away for education was one of the toughest decisions of my life. My great-grandparents, the only two humans I've been close to and in contact with for my entire life needed me. My grandfather (kaaga) had a stroke and needed me to move home with him because he didn't want to stay in hospital. My grandmother (kaala) was diabetic and flirting with dementia. I moved back into our country home. We were eating healthier, drinking more water, my kaalas blood sugar was normal and she was actively recalling memories from when I was young and her own childhood. The opportunity came for me to go to school, my kaala and kaaga were healthy and wanted me to go back to school. I moved to
Bozeman. When I completed my undergrad degree I immediately transitioned into graduate school. By accident, I was introduced to Suzanne Held, by my wife. Suzanne said, "have you heard of Messengers for Health, do you know Alma McCormick?" That's my auntie! I began working with MFH in 2015, have attended community meetings and developed relationships with program staff and the CAB. I completed the work described in this paper while a graduate student in Community Health at MSU.

Alma Knows His Gun McCormick is the Executive Director of the non-profit organization $\mathrm{MFH}$ and a member of the Apsáalooke Nation who fluently speaks her language. Her compassion for working in health stems from her personal experience of losing her daughter to cancer. Suzanne Held is a professor in Community Health who is white, originally from Wisconsin and sees that health disparities exist because of colonization and current policies that privilege whites and wants to do her part toward a healthier and more equitable future. Alma and Suzanne have worked together since 1996. John Hallett is a white resident physician in Family and Community Medicine at University of California Davis. He began working with the project in 2013 while attending MSU, where he deepened his commitment to serving with communities, prior to attending University of Colorado School of Medicine. Shannen Keene received her master's degree in Community Health at MSU and started working with the project in 2017 and currently works at the Urban Indian Health Institute. Her commitment to promoting health equity stems from her Filipino-American identity. Other team members include our $\mathrm{CAB}$, the ten mentors who facilitate the Báa nnilah program, and other faculty and students from MSU.

This paper describes the development and application of a goal-setting tool specific to and appropriate for the Apsáalooke within the Báa nnilah program. Our aim was to use an IRM and CBPR approach, moving toward health and wellness using the strengths of the community.

\section{Methods}

This is a descriptive journey of IRM planting seeds 
through CBPR. This journey co-relates with the story of a two spirit Apsáalooke woman named Iitáa Dáakuash, fancy dancing with the predominantly white institution and the power found in Apsáalooke relationships. As a research paradigm, IRM are comprised of four interrelated concepts: ontology (nature of reality); epistemology (nature of knowing); axiology (nature of moral judgement); and methodology (nature of uncovering) (Wilson, 2008). Enacting these concepts in research is difficult and it is culturally inappropriate and impossible to both use these concepts and outline a concrete, linear process as is expected in Western research. Appropriately using these concepts in research is more like a fancy dancer who hears, twirls, and spins to the beat of the community.

Thus, the method of developing an Indigenous goal-setting tool happened through relational accountability or honoring relationships. It is necessary in IRM for research processes to include spending time together, talking about history, culture, commonalities, and disparities; all the while building relationships. Methods come from relationships and stories. Honoring this, the first author shares an excerpt of her story of using IRM to develop a goal-setting tool.

I come from a 5-generation family, my great-grandmother raised me, I grew up in the country on our reservation dancing at powwows, playing/coaching basketball games, getting food for kaalas and kaagas at family reunions, old people's feasts, and birthday parties. My great grandma, Ferole Mae is her name, she is known as "Aloe Vera Mae." She knows everyone, we stopped and had coffee with so many people I could never know who is all a part of my family. Growing older, I became the granddaughter who invited you in, made sure the house was cozy and brewed a cup of coffee, made sure we had donuts for story time and catching up. Every weekend I would come back to our country home and be ready for visitors. Today things have changed, and we don't visit as much. I became a member of MFH in 2015 through finishing my undergrad degree. I began going to our community meetings with the program. I saw so many Crows that I didn't know, and as we visited, they found out who my grand- ma was, where I played ball, and we learned how we are connected to each other. In each of our community meetings, I found relations with many of our team members; that I went through school with their children, that they are related to my grandma, or that they teach where I went to high school. I loved these community meetings, we were gathering again, and so, I began bringing "Aloe Vera Mae." I could feel the respect given when my grandma got wheeled into the room. I was proud. My grandma spoke and said the things we needed to hear to solidify our program. She said, "I used to be in community meetings... we haven't had them in years. You are doing a good thing here." It was powerful and everyone felt it. That respect, relationship, and history replenished our blood memory and from this, the idea of Counting Coup as our goal-setting tool was born.

The method was the stories shared in our meetings and the relationships that were built. We went back to our kaalas and kaagas of the past, back to before there were chronic illnesses. Back to the days of living together, thriving, sharing each other's experiences, and providing for each other. These meetings ignited our blood memory, strengthened our identities, and reminded us of a time when we were a strong and healthy people. When we went into battle, came away unharmed, and Counted Coup. We went back in time and took ownership of this old-time war deed for the future of our tribe. Today, one of our greatest enemies has become chronic illness; our stories paint the battlefields of our illnesses. And so we Count Coup.

Our community has a bridge between our Ancestors and present day in Joe Medicine Crow who, as a soldier in World War II, Counted Coup in battle. We picture him stealing horses from a German camp singing a traditional Crow honor song as he rode off. We engage our historical beings through our Ancestors and the concept of Counting Coup and what that means today.

\section{Results}

Báa nnilah (advice) is the name of the chronic illness self-management program developed to im- 
prove community health and wellness. It weaves the white world and Indigenous worlds to have one goal, to make stronger people. The program includes seven gatherings, facilitated by a community member (Aakbaabaaniilea, the ones who give advice) who is managing a chronic illness, and who has recruited family and people they knew who could benefit from this program. Gathering topics include: beginning the Báa nnilah journey; ongoing health conditions; strong heart daasachchuchik; healthy food and physical activity; positive healthcare experiences; healthy communication and overcoming challenges; and closing and graduation ceremony. Gatherings start with group members arriving with their program binders and Counting Coup journals. We gather for a healthy meal and to catch up. We smudge, check in, poke fun at one another, and say what we need before we focus on gathering topics.

Báa nnilah gatherings took place in accessible community spaces across and near the Apsáalooke Nation. Each of the ten Aakbaabaaniilea led two groups of ten participants for a total of 200 participants. Gatherings were held bi-weekly and lasted approximately three hours. Participants received health-related incentives (e.g., walking shoes, activity tracker) and gas vouchers to assist with transportation. Most importantly, participants had the opportunity to restore their relationships or kinship bonds rooted in their ancestral history. Additional details about program content and approach can be found at Held et al., (2019) and Schure et al. (2020).

Through these gatherings we share stories, laugh, experience community setbacks and possible solutions, care for the younger generations and inquire about family members, speak Apsáalooke to one another, and form a bond not to be forgotten. We open each gathering with a story, we share, ask questions, encourage one another, and listen to our ancestral history through our blood memory. Our program binders keep us on task by providing us with meeting outlines, a story, and health information sheets. The power in our methodologies depict the story of how we, as Indigenous people, do things, know things, and engage survivance.

The Counting Coup tool is used in our program as a part of a journal that each participant receives at the first program gathering. See Figure 1 below of one of the pages of feathers that is at the end of each gathering. In these feathers, participants write ways in which they look to Count Coup (make goals) that will enable them to fulfill their Apsáalooke roles in the community. The word Apsáalooke encompasses a culture that cannot be written, rather it is understood.

Coup feathers can pertain to areas of everyday life that correspond to program content areas. In the introduction of the journal, we talk about what this new way of thinking about Counting Coup means to us as a people:

As Apsáalooke, it is our desire to live a long, healthy life. We value each other and we value life. We want to be here for our loved ones. We want to see our grandchildren, our great grandchildren, our great-great grandchildren. We want to be here as a clan uncle or clan auntie. We want to be able to fulfill our roles in our family and in our community. Consider our ancestors, who lived long, healthy lives, and could fulfill their roles being resilient, strong, and proud. Our ancestors had hope for the future and for the ones to come. We are the ones our ancestors prayed for. We call this Counting Coup because in the old days when our warriors would achieve a brave war deed, they could add a feather to their coup stick. They could Count Coup by touching the enemy with their hand or coup stick and come away unharmed. Counting Coup is about making goals for ourselves to enable us to fulfill our roles. We are now riding into battle with our health and we look to find more ways we can Count Coup in this battle. To be resilient, healthy, and strong for our family, our community, and for the ones to come. The feathers we receive will enable us to see our future generations and to carry on as proud Apsáalooke. The Báa nnilah program encourages each of us to revive the strong ties among the Apsáalooke, to revive ourselves and become stronger and healthier in body, mind, and spirit. To live longer lives and be role models in our communities. We can do this together, supporting and nurturing one another. It can be helpful to write down barriers or challenges to gathering your 
feathers and ideas for how you can overcome them. Below are ideas for receiving feathers.

Visit a relative, walk, bike, talk with others in Apsáalooke, talk with an Elder, ask about history, eat the same as the old timers, share a meal with others, retell a story like Old Man Coyote or creation stories, gather food, hunt, pick berries, plant seeds, eat more fruits and vegetables, eat less desserts, eat less carbohydrates like white breads and bagels, avoid pop and alcohol.

Figure 1. Inside page of Counting Coup journal showing the area to write in feathers (goals).

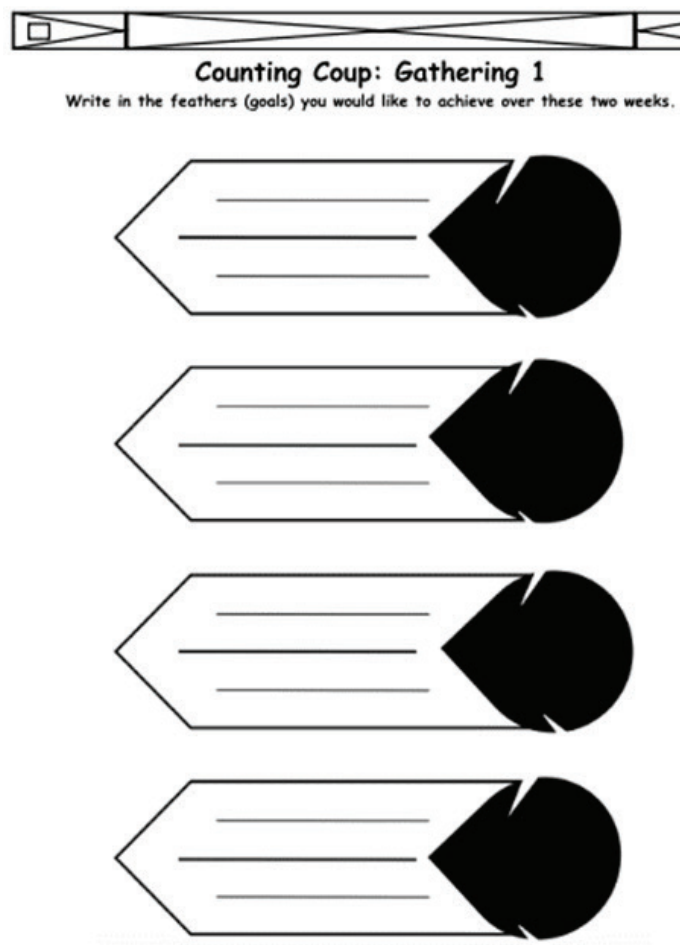

With our Counting Coup tool, there are no numerical scales to assess how effective participants feel a goal may be for them, or to state their level of commitment. The idea is to imagine the warriors and imagine themselves going into battle with their chronic illness and saying, "I know I am sick for so many reasons. How can I be more like the warriors?" Participants look to gather feathers by showing superiority over their chronic illnesses. How can they touch this enemy, humiliate this enemy? It places participants in a time where they know what they need, igniting blood memories to be the ones their Ancestors prayed for. This gets them to a deeper meaning of their chronic illnesses, the paths they have traveled to them and how they can incorporate their history through a war deed to self-motivate toward healing and health. Counting Coup acknowledges Apsáalooke original ways of life and enables community members to find a motivation that can only be measured through story. As Indigenous peoples, we want and desire to Count Coup (accomplish our goals) and make our Ancestors proud. Counting Coup comes from our history and our relationships with each other. It is in our blood to listen to our culture.

\section{Stories of Counting Coup}

At the first gathering, participants join into supportive partnerships of two or three. We ask the partners to be in touch with each other at least once per week during the program. In each of the subsequent six gatherings, partners share stories with each other to support and provide encouragement on how they are Counting Coup (Kovach, 2009; Wilson, 2008).

Participants shared many ways of how they Counted Coup. One participant dealt with Post Traumatic Stress Disorder (PTSD) from a horrific car accident and said she would never drive again. Through the impact of this program and through Counting Coup, the feather she gathered was to be able to drive again. Another participant, through gathering feathers of healthy eating, cutting down on sugar-sweetened beverages, and exercising more, lost 50 pounds. One participant received a gift of a guitar from her father, who taught her how to play. Her father died tragically and when this happened, she closed the guitar case and put it away. Through the program, she discovered repressed feelings from this loss, had a safe space to talk, and realized she could connect with him through the guitar, opened the case, and began to play again. Other common ways participants Counted Coup included drinking more water, having better communication with their doctors, and improving relationships with family members.

One of the characteristics of Indigenous communities is that community members live in the present with the philosophy of survivance. This is in contrast to the future orientation embedded in Western goal-setting. Survivance captures the resistance of assimilation through Indigenous communities surviving and thriving in their cultures (Deloria, 1970). Moreover, this historical value is woven into 
contemporary Indigenous identity, which strengthens community connections and relational accountability. We developed a tool that could offer rewards (sharing the gathering of feathers) in the present.

\section{Limitations}

Counting Coup implementation has various limitations. First, program facilitators need to have a relationship with participants due to Counting Coup's foundation in relational accountability. Without a strong relationship to the facilitator, participants' motivation for gathering feathers may not be rooted in Indigenous identity and ways of being. Additionally, the environmental context may pose difficulties for participants in moving towards behavior change. Potential barriers may include political tension, extreme weather (e.g., fires, flooding, snow), limited resources related to meeting basic needs, and cultural taboos (e.g., communication between genders).

\section{Reflections}

Through the Counting Coup goal-setting tool, participants awakened a connection to their Ancestors. Counting Coup reinforced the community's history in a positive way and reconnected community members to this history by realizing how much healthier the community was before colonization. It reminded the community of their history and related it to their well-being. Community members inspired each other with their rich culture and took ownership of Counting Coup again in contemporary time.

Additionally, sharing challenges and failures while Counting Coup allowed participants to process and share the day-to-day experience of having a chronic illness and created avenues of support. In this way, Counting Coup assisted program participants in conceptualizing the daily management of chronic illnesses, which often feels abstract and difficult to grasp.

There are current goal-setting tools used in Western-developed chronic illness self-management programs. However, in Indigenous cultures, the development of goals can feel like an isolating exercise. Rather than approaching goals as specific objectives to achieve outside of their normal routine, individuals may use Counting Coup to shape a contemporary way of being that is connected to Ancestors and history.

Other goal-setting tools developed for use with Indigenous populations included a collaborative goal-setting tool that engaged an individual's family and other professionals (Watts \& Carlson, 2002); an adapted section of a self-management program called "My Health Story" (Battersby et al., 2018); and a medicine wheel that was adapted into the Navajo Goal Wheel that integrated Navajo philosophies (Garner, Bruce, \& Stellern, 2011).

\section{Conclusions}

From our experience, we believe research is strongest and most impactful to community health when it originates from an Indigenous paradigm. "An Indigenous paradigm comes from the fundamental belief that knowledge is relational. Knowledge is shared with all of creation" (Wilson, 2001, p. 176). Báa nnilah was developed through relationships shaped by the Apsáalooke culture and is building a bridge between Indigenous and Western ways to develop programs inclusive to Indigenous communities. In other words, methods are circular like the movements of a fancy dancer and can be grounded in IRM and CBPR approaches. By bringing together these diverse ways of knowing in daily practice, researchers are able to create and encourage new ways of doing research (Botha, 2011). We hope that this work will inspire other Indigenous communities to decolonize Western goal-setting tools by integrating their unique histories and languages into future community-based evaluation efforts.

\section{References}

Antonucci, J. (2008). A new approach to group visits: Helping high-need patients make behavioral change. Family Practice Management, 15(4), A6-A8. https://www.aafp.org/fpm/2008/0400/ fpm20080400pa6.pdf

Australian Better Health Initiative. (2009). Capabilities for supporting prevention and chronic condition self-management: A resource for educators of primary health care professionals. Flinders University. http://www.flinders.edu.au/medicine/ fms/sites/FHBHRU/documents/publications/Capabilities\%20Self-Management $\% 20$ Resource. pdf 
Australian Government Department of Health and Ageing \& Flinders University. (2009). Capabilities for supporting prevention and chronic condition self-management: A resource for educators of primary health care professionals. Adelaide: Commonwealth of Australia.

Barlow, J., Wright, C., Sheasby, J., Turner, A., Hainsworth, J. (2002). Self-management approaches for people with chronic conditions: A review. Patient Education and Counseling, 48, 177-187. https://doi. org/10.1016/S0738-3991(02)00032-0

Battersby, M., Lawn, S., Kowanko, I., Bertossa, S., Trowbridge, C., ... Liddicoat, R. (2018). Chronic condition self-management support for Aboriginal people: Adapting tools and training. Australian Journal of Rural Health, 26(4), 232-237. https://doi.org/10.1111/ajr.12413

Blue Bird Jernigan, V. (2010). Community-based participatory research with Native American communities: The Chronic Disease Self-Management Program. Health Promotion Practice, 11(6), 888-899. https://doi. org/10.1177/1524839909333374

Botha, L. (2011). Mixing methods as a process towards indigenous methodologies. International Journal of Social Research Methodology, 14(4), 313-325. https://doi. org/10.1080/13645579.2010.516644

Brayboy, B. (2005). Toward a tribal critical race theory in education. Urban Review, 37(5), 425-446. https://doi.org/10.1007/ s11256-005-0018-y

Centers for Disease Control and Prevention. (2016). Summary Health Statistics: $\mathrm{Na}$ tional Health Interview Survey: 2014. Table A-4. http://www.cdc.gov/nchs/ nhis/shs/tables.htm

Deloria, V., Jr. (1970). We talk, you listen: New tribes, new turf. New York, NY: Macmillan.

Duran, E., \& Firehammer, J. (2015). Story sciencing and analyzing the silent narrative between words: Counseling research from an Indigenous perspective.
In R. Goodman \& P. Gorski (Eds.), Decolonizing "Multicultural" Counseling and Psychology: Visions for Social Justice Theory and Practice (pp. 85-97). New York: Springer-Verlag.

Garner, H., Bruce, M., \& Stellern, J. (2011). The goal wheel: Adapting Navajo philosophy and the medicine wheel to work with adolescents. The Journal for Specialists in Group Work, 36(1), 62-77. https://doi-org.myaccess.library.utoronto. $\mathrm{ca} / 10.1080 / 01933922.2010 .537735$

Gordon A., \& Oddo V. M. (2012). Addressing child hunger and obesity in Indian Country: Report to Congress. Final report submitted to the U.S. Department of Agriculture, Food and Nutrition Service. Princeton, NJ: Mathematica Policy Research. https://www.mathematica.org/-/media/ publications/pdfs/nutrition/child_hunger_obesity.pdf

Hallett J., Held, S., Knows His Gun McCormick, A., Simonds, V., Real Bird, S., Martin, C., ... Trottier, C. (2017) What touched your heart? Collaborative story analysis emerging from an Apsáalooke cultural context. Qualitative Health Research, 27(9), 1267-1277. https://doi. org/10.1177/1049732316669340.

Held, S., Hallett, J., Schure, M., McCormick, A., Allen, S., Milne-Price, S., Trottier, C., Bull Shows, B., Other Medicine, L., \& Inouye, J. (2019). Improving chronic illness self-management with the Apsáalooke Nation: Development of the Báa nnilah Program. Social Science \& Medicine. https://doi.org/10.1016/j. socscimed.2019.112583

Institute for Healthcare Improvement. (2018). Changes. http://www.ihi.org/resources/Pages/ Changes/SetandDocumentSelfManagementGoalsCollaborativelywithPatients.aspx

Institute of Medicine. (2012). Living well with chronic illness: A call for public health action. Washington, DC: The National Academies Press. https://www.nap.edu/catalog/13272/living-wellwith-chronic-illness-a-call-for-public-health

Israel, B., Schulz, A., Parker, E., \& Becker, A. (1998). Review of community-based research: Assessing partnership approaches to improve public health. Annual Review of Public Health, 19, 173-202. https://doi.org/10.1146/annurev. publhealth.19.1.173 
Kovach, M. (2009). Indigenous methodologies: Characteristics, conversations, and contexts. Toronto: University of Toronto Press.

LaVeaux, D. \& Christopher, S. (2009). Contextualizing CBPR: Key principles of CBPR meet the Indigenous research context. Pimatisiwin: A Journal of Aboriginal and Indigenous Community Health, 7(1), 1-25.

Linderman, F. B. (2003). Pretty-Shield: Medicine woman of the Crows. Lincoln, NE: University of Nebraska Press.

Locke, E., \& Latham, G. (1990). A theory of goal setting \& task performance. Englewood Cliffs, NJ: Prentice-Hall, Inc.

Locke, E. \& Latham, G. (2006). New directions in goal-setting theory. Current Directions in Psychological Science, 15(5), 265-268. https://doiorg/10.1111/j.1467-8721.2006.00449.x

Lorig, K., Ritter, P., Ory, M., Whitelaw, N. (2013). Effectiveness of a generic chronic disease self-management program for people with type 2 diabetes. The Diabetes EDUCATOR, 39(5), 655663. https://doi.org/10.1177/0145721713492567

Martin, K., \& Mirraboopa, B. (2003) Ways of knowing, being and doing: A theoretical framework and methods for Indigenous and indigenist re-search. Journal of Australian Studies, 27(76), 203-214. https://doi.org/10.1080/14443050309387838

Medicine Crow, J. (1992). From the heart of the Crow Country: The Crow Indians' own stories. New York, NY: Orion Books.

Medicine Crow, J., \& Viola, H. J. (2006). Counting Coup: Becoming a Crow Chief on the Reservation and Beyond. Washington, DC: National Geographic.

Minkler, M. \& Wallerstein, N. (2008). Community-based Participatory Research for Health: From Process to Outcomes (2nd ed.). San Francisco, CA: Jossey-Bass.

Nuovo J. (Ed.). (2007). Chronic Disease Management. New York City: Springer.

Schure, M. B., Allen, S., Trottier, C., McCormick, A., Other Medicine, L., Castille, D., \& Held, S. (2020). Daasachchuchik: A trauma-informed approach to developing a chronic illness self-management program for the Apsáalooke people. Journal of Health Care for the Poor and Underserved, 242, 992-1006. https://doi.org/10.1016/j. socscimed.2019.112583

Shanks, C., Smith, T., Ahmed, S., \& Hunts, H. (2016). Assessing Foods Offered in the Food Distribution Program on Indian Reservations (FDPIR) Using Healthy Eating Index-2010. Public Health Nutr., 19(7), 1315-1326. https://doi.org/10.1017/ S1368980015002359

Snell, A. H. (2000). Grandmother's grandchild: My Crow Indian life (B. Matthews, Ed.). Lincoln, NE: University of Nebraska Press.

Sobeck, J. L., Chapleski, E. E., Fisher, C. (2003). Conducting research with American Indians: A case study of motives, methods and results. Journal of Ethnic and Cultural Diversity in Social Work, 12(1), 69-84. https://doi.org/10.1300/ J051v12n01_04

Warren, K., Coulthard, F., \& Harvey P. (2005). Elements of Successful Chronic Condition Self-Management Program for Indigenous Australians. 8th National Rural Health Conference. https:// www.ruralhealth.org.au/8thNRHC/Papers/warren_coulthard.pdf

Watts, E. \& Carlson, G. (2002). Practical strategies for working with Indigenous people living in Queensland, Australia. Occupational Therapy International. 9(4), 277-293. https://doi.org/ 10.1002/oti.169

Wilson, S. (2001). What is an Indigenous research methodology? Canadian Journal of Native Education, 25(2), 175-179.

Wilson, S. (2008). Research is ceremony: Indigenous research methods. Black Point, Nova Scotia: Fernwood Publishing. 